Bruno de Andrade Rodrigues

Estudo Descritivo dos Usos do Clítico Ihe na Variedade formal do Português DISSERTAÇÃO DE MESTRADO DEPARTAMENTO DE LETRAS
Programa de Pós-Graduação em Estudos
da Linguagem 


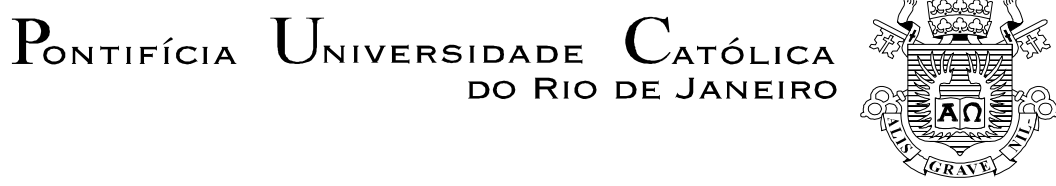

Bruno de Andrade Rodrigues

\title{
Estudo Descritivo dos Usos do Clítico Ihe na Variedade formal do Português
}

\begin{abstract}
Dissertação apresentada ao Programa de PósGraduação em Letras da PUC-Rio como requisito parcial para obtenção do grau de Mestre em Letras. Aprovada pela Comissão Examinadora abaixo assinada.
\end{abstract}

Orientadora: Eneida do Rego Monteiro Bomfim

Rio de Janeiro

Março de 2007 


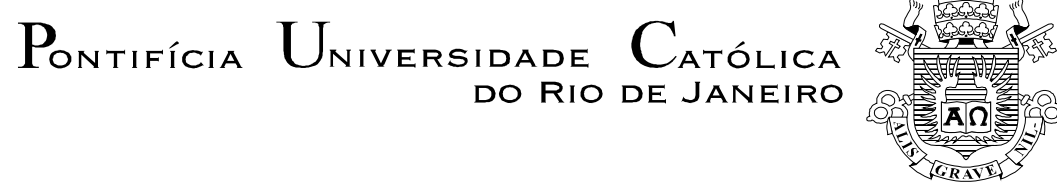

Bruno de Andrade Rodrigues

\title{
Estudo Descritivo dos Usos do Clítico Ihe na variedade formal do Português
}

Dissertação apresentada como requisito parcial para obtenção do grau de Mestre pelo programa de Pós-graduação em Letras do Departamento de Letras do Centro de Teologia e Ciências Humanas da PUC-Rio. Aprovada pela Comissão Examinadora abaixo assinada.

\author{
Profa. Eneida do Rego Monteiro Bomfim \\ Orientadora \\ Departamento de Letras - PUC-Rio
}

Prof. Ricardo Borges Alencar

Departamento de Letras - PUC-Rio

Prof. José Carlos Santos de Azeredo

Universidade Estadual do Rio de Janeiro - UERJ

Prof. Paulo Fernando Carneiro de Andrade Coordenador Setorial do Centro de Teologia e Ciências

Humanas - PUC-Rio

Rio de Janeiro, de de 
Todos os direitos reservados. É proibida a reprodução total ou parcial do trabalho sem autorização do autor, do orientador e da universidade.

\section{Bruno de Andrade Rodrigues}

Graduou-se em Letras no Centro Universitário da Cidade, em 2004, onde foi monitor de Língua Portuguesa. Desenvolveu trabalhos nas áreas de Sintaxe e de Teoria Lexical, tendo apresentado trabalhos na área de Português L2 em congressos. Interessa-se por diversas áreas da ciência linguiística; especialmente, pelas áreas de Sintaxe, Morfologia e Semântica, no domínio da gramática; e pela área de Sociolingüística.

Ficha Catalográfica

Rodrigues, Bruno de Andrade

Estudo descritivo dos usos do clítico lhe na variedade formal português / Bruno de Andrade ; orientadora: Eneida do Rego Mont Bomfim. - 2007.

$190 \mathrm{f.} ; 30 \mathrm{~cm}$

Dissertação (Mestrado em Letras)-Pontifícia Universidade Católic. Rio de Janeiro, Rio de Janeiro, 2007.

Inclui bibliografia

1. Letras - Teses. 2. Sintaxe. 3. Discurso. 4. Valências. Funcionalismo. 6. Pronome. 7. Cliticização. 8. Objeto indireto. Gramática. I. Bomfim, Eneida do Rego Monteiro. II. Pontif Universidade Católica do Rio de Janeiro. Departamento de Letras. Título. 
Jesus Cristo pela minha vida.

Aos meus pais amados pelas lições de humildade, respeito e perseverança. 


\section{Agradecimentos}

À professora Eneida do Rego Monteiro Bomfim pela preciosa e dedicada orientação.

A todos os professores que contribuíram para a minha formação acadêmica.

Ao professor e amigo Ricardo Borges Alencar pelo incentivo e inestimável ajuda.

À Chiquinha pela solicitude e apoio durante todo o curso.

Aos meus pais e irmão pela confiança e apoio nos momentos de desalento.

À minha amada madrinha Dely, pela confiança e carinho.

Aos amigos Pedro, Joelcio, Fátima, Aline e Larissa que me ajudaram a avivar meu espírito.

Aos amigos Daniel e Antônia pelos inúmeros acessos à Internet.

Ao $C N P Q$ pela concessão da bolsa.

Ao meu amado padrinho Manoel Augusto (in memorian) pela orientação espiritual constante.

Muito obrigado. 


\section{Resumo}

Rodrigues, Bruno de Andrade; Bomfim, Eneida do Rego Monteiro. Estudo Descritivo dos Usos do Clítico Lhe na Variedade Formal do Português. Rio de Janeiro, 2007. 190p. Dissertação de Mestrado Departamento de Letras, Pontifícia Universidade Católica do Rio de Janeiro.

Este trabalho visou à descrição do comportamento sintático-discursivo do pronome clítico lhe na variedade formal da modalidade escrita do português. Preocupada com a investigação das propriedades sintáticas e semânticas da atualização do lhe, a análise assentou-se na devida separação entre os planos semântico e formal, os quais foram associados para efeito de determinação das funções sintático-discursivas desse pronome. A pesquisa, de cunho funcionalista, foi empreendida sob o pressuposto de que o chamado objeto indireto, variedade de dativo e função tipicamente exercida pelo pronome lhe, constitui uma função sintática heterogênea e não bem definida que recobre indevidamente, na gramática tradicional, outros usos de dativo. Assim, concluiu-se que o pronome lhe cumpre outras funções sintático-discursivas não contempladas na tradição e nos estudos mais recentes, que não podem ser reunidas sob o rótulo de objeto indireto.

\section{Palavras-chave}

Sintaxe; Discurso; Valências; Funcionalismo; Pronome; Cliticização Objeto indireto; Gramática; Semântica; Dativos. 


\section{Abstract}

Rodrigues, Bruno de Andrade; Bomfim, Eneida do Rego Monteiro. Estudy Descritive of the Uses of Clitic Lhe in Formal Variety Portuguese. Rio de Janeiro, 2007. 190p. Dissertation - Departamento de Letras, Pontifícia Universidade Católica do Rio de Janeiro.

This work aimed the description of the syntactic-discursive behavior of the clitic pronoun lhe in the formal variety of the written Portuguese modality. Concerned with the investigation of the semantic and syntactic properties of the lhe utilization, the analysis focus on the very separation between the semantic and formal plans, which have been associated in order to determine the syntactic-discursive functions of this pronoun. Our research, of a functionalist basis, was done after the presupposition that the so called indirect object, variety of dative and function typically performed by the the pronoun, constitute a heterogeneous and not well defined syntactic function that covers unduly, in the traditional grammar, other dative uses. Therefore, we concluded that the lhe pronoun has got other syntactic-discursive functions pondered neither by the grammar tradition nor by the more recent studies, that can not be assembled under the same label of indirect object.

\section{Keywords}

Syntax; Discourse; Grammar; Functionalism; Pronoun; Function; Dative Semantics; Indirect object; Valency. 


\section{Sumário}

1. Introdução ….......................................... 10

1.2. - Metodologia ............................................ 19

2. O Funcionalismo: fundamentação teórico

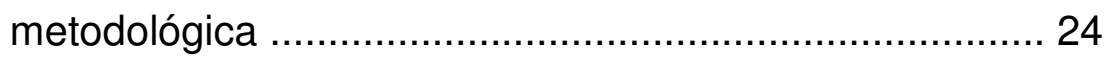

2.1. - O modelo funcionalista de Michael A.K. Halliday .. 29

2.1.1. O conceito de função

2.2. - O modelo funcionalista Simon Dik ......................... 38

3. A Gramática de valências ........................................... 42

3.1. O conceito de valência

3.2. Alguns tipos de actantes ............................................ 48

4. O objeto indireto na tradição gramatical ........................ 49

4.1. Soares Barbosa

4.2. Maximino Maciel .................................................... 50

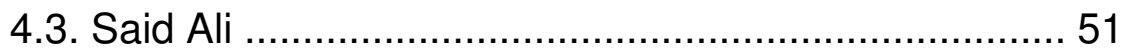

4.4. Joaquim Mattoso Câmara Jr. ..................................... 54

4.5. Carlos Henrique da Rocha Lima ............................... 56

4.6. Adriano da Gama Kury …………............................. 61

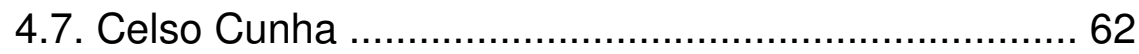

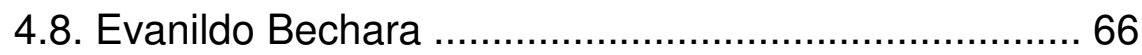

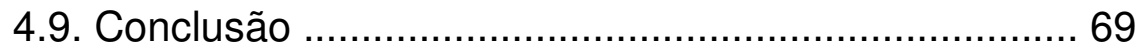

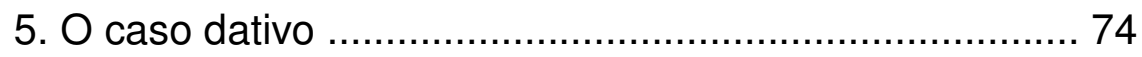

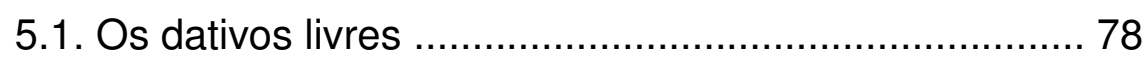

5.1.1. O dativo de posse ............................................ 80

5.1.2. O dativo commodi et incommodi (ou de interesse)... 82

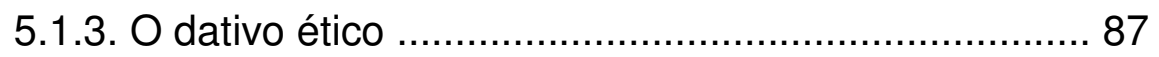

5.1.4. Considerações finais ............................................... 88 
6. Análise do comportamento sintático-discursivo do pronome the ......................................................... 89

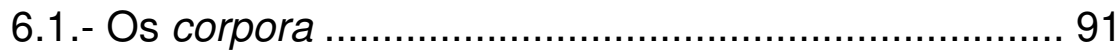

6.2. - O verbo suporte e a expressão cristalizada ............ 92

6.3. - Análise dos corpora ............................................. 111

6.3.1 Verbos que se constroem tradicionalmente com o chamado objeto indireto

6.3.2. Outras considerações

6.4. - Verbos que se constroem com objeto indireto

cujo núcleo é um substantivo [ - animado] 131

6.5. - Os dativos livres 135

6.5.1. O chamado dativo de posse

6.5.2. O chamado dativo de interesse 142

6.5.3. Os casos dos verbos aparecer e marcar 154

6.6. - Verbos que selecionam complemento introduzido por preposição diferente de a e cliticizável em lhe 157

6.7.- O emprego de lhe em construções várias 160

6.7.1. Construções formadas por verbo + SP

6.7.1.2 Uma nota histórica 164

6.8.- Construções formadas por verbo ser $+\underline{\text { adjetivo }}$......168

6.8.1. Construções com verbo semanticamente esvaziado 170

6.8.2. Os exemplos de lhe como substituto anafórico de substantivo [ - animado] na literatura lingüística 179

6.9. - Uma nota final: registro histórico 181

7. Conclusão 183

8. Bibliografia 189 